\title{
Preparation and Characterization of Nafion Composite Membranes Containing 1-ethyl-3-methylimidazolium Tetracyanoborate
}

\author{
Mun-Sik Shin and Jin-Soo Park* \\ Department of Environmental Engineering, College of Engineering, Sangmyung University, 31 Sangmyungdae-gil, \\ Dongnam-gu, Cheonan, Chungnam Province, 330-712 Republic of Korea
}

(Received January 13, 2012 : Accepted January 27, 2012)

\begin{abstract}
The composite membranes using Nafion as matrix and 1-ethyl-3-methylimidazolium tetracyanoborate (EMITCB) as ion-conducting medium in replacement of water were prepared and characterized. The amount of EMITCB in Nafion varied from 30 to $50 \mathrm{wt} \%$. The composite membranes are characterized by ion conductivity, thermogravitational analyses (TGA) and small-angle X-ray scattering (SAXS). The composite membranes containing EMITCB of $40 \mathrm{wt} \%$ showed the maximum ionic conductivity which was $\sim 0.0146 \mathrm{~S} \mathrm{~cm}^{-1}$ at $423.15 \mathrm{~K}$. It is inferred that the decrease in ionic conductivity of all the composite membranes might be due to the decomposition of a tetracyanoboric acid formed in the composite membranes. The results of SAXS indicated that the ionic clusters to conduct proton in the composite membranes were successfully formed. In accordance with the results of ionic conductivity as a function of a reciprocal temperature, SAXS showed a proportional decrease in scattering maximum $q_{\max }$ as the amount of EMITCB increases in the composite membranes, which results in the increase in ionomer cluster size. The TGA showed no significant decomposition of the ionic liquid as well as the composite membranes in the range of operating temperature $\left(120-150^{\circ} \mathrm{C}\right)$ of high temperature proton exchange membrane fuel cells (HTPEMFC). As a result, EMITCB is able to play an important role in transferring proton in the composite membranes at elevated temperatures with no external humidification for proton exchange membrane fuel cells.
\end{abstract}

Keywords : Composite membrane, Nafion, 1-ethyl-3-methylimidazolium tetracyanoborate, Proton exchange membrane fuel cell, Ionic liquid

\section{Introduction}

Composite membranes containing ionic liquids have been extensively studied in recent literature as alternative polymer electrolytes for high temperature proton exchange membrane fuel cells (HTPEMFCs). ${ }^{1-6}$ ) Motivation to replace Nafion arises from various advantages of PEMFC systems operating at higher temperature than normal PEMFC operating temperature $\left(70-80^{\circ} \mathrm{C}\right)$ such as reduced size of a radiator by widening temperature difference between operating and atmosphere temperature, mitigated complexity by removing external humidification units, no need of $\mathrm{CO}$ clean-up units in fuel processors, etc. ${ }^{7)}$ However, Nafion membranes cannot be used at higher temperatures $\left(>80^{\circ} \mathrm{C}\right)$

*E-mail: energy@smu.ac.kr since the ionic conductivity is strongly dependant on humidity and thus an increase in temperature above $80^{\circ} \mathrm{C}$ leads to a loss in fuel cell performance due to a drastic decrease in ionic conductivity by the loss of water by evaporation. ${ }^{8)}$ This problem can be addressed by using membranes which do not require water for ionic conduction but use an alternative solvent with higher boiling point and other necessary properties. ${ }^{6}$ )

E. Cho et al. ${ }^{1)}$ have reported that the characteristics of composite membranes containing ionic liquids were very similar to those of water swollen membranes, which are an increase in ionic conductivity with an increase in the degree of sulfonation of polymers and in the content of ionic liquids. S.S. Sekhon et al. ${ }^{2-4)}$ have concluded that the morphology studies of composite membranes containing ionic liquids by small-angle X-ray scattering (SAXS) confirmed the formation of ionic 
clusters in the composite membranes and the proportional correlation between the size of clusters obtained by SAXS and ionic conductivity. The composite membranes containing ionic liquids should have more content of ionic liquids to get higher ionic conductivity, but more content of ionic liquids causes poor mechanical strength and significant gas permeation. In an effort to reduce the content of ionic liquids without significant loss in ionic conductivity, J.-S. Baek et $a .^{5)}$ have found that the addition of the acids with common anion of ionic liquids into the composite membranes containing ionic liquids brought about an increase in the size of ionic clusters by SAXS and in ionic conductivity, and J.-S. Park et $\left.a l .{ }^{6}\right)$ have reported that annealing of the composite membranes also resulted in the same observation.

Recently, the room temperature ionic liquid (RTIL), 1-ethyl-3-methylimidazolium tetracyanoborate (EMITCB), has been being highlighted due to its technologically favorable properties as high chemical and thermal stability and low viscosity. In particular, the IL can be a promising candidate as electrolyte of dye sensitized solar cells due to high vapor pressure and better ionic conductivity. Our research group mainly used 1-ethyl-3methylimidazolium tetrafluoroborate $\left(\mathrm{EMIBF}_{4}\right)$ for preparation of the Nafion composite membranes reported in the recent literature due to good ionic conductivity and in other words low viscosity. ${ }^{1-6)}$ It was also reported that the use of ILs having higher ionic conductivity is a way to increase ionic conductivity of the composite membranes. ${ }^{1)}$ Table 1 shows the main properties of two different ILs. The EMITCB shows higher ionic conductivity due to lower viscosity.

In this study, the composite membranes containing EMITCB as ion-conducting medium were prepared using Nafion dispersion as polymer matrix by solution casting with various amounts to investigate if EMITCB can be used in the composite membranes for high temperature proton exchange membrane fuel cells (HTPEMFCs) with no external humidification. In order to study the effect of the use of EMITCB for the composite membranes, the properties such as ionic conductivity, thermogravitational analysis and small-angle X-ray scattering were analyzed.

\section{Experimental}

\subsection{Polymer}

The Nafion solution (perfluorosulfonic acid/TFE
Table 1. Properties of two ionic liquids ${ }^{15)}$

\begin{tabular}{|c|c|c|}
\hline Properties & $\begin{array}{l}\text { 1-ethyl-3- } \\
\text { methylimidazolium } \\
\text { tetrafluoroborate } \\
\left(\mathrm{EMIBF}_{4}\right)\end{array}$ & $\begin{array}{l}\text { 1-ethyl-3- } \\
\text { methylimidazolium } \\
\text { tetracyanoborate } \\
\text { (EMITCB) }\end{array}$ \\
\hline Boiling point $\left({ }^{\circ} \mathrm{C}\right)$ & $>280$ & NA \\
\hline Melting point $\left({ }^{\circ} \mathrm{C}\right)$ & 14 & 13 \\
\hline $\begin{array}{l}\text { Molecular weight } \\
\qquad\left(\mathrm{g} \mathrm{mol}^{-1}\right)\end{array}$ & 197.97 & 226.05 \\
\hline Density* $\left(\mathrm{g} \mathrm{cm}^{-3}\right)$ & 1.304 & 1.040 \\
\hline Viscosity* (cP) & 60 & 22 \\
\hline $\begin{array}{l}\text { Conductivity* } \\
\left(\mathrm{mS} \mathrm{cm}^{-1}\right)\end{array}$ & 11.4 & 13.0 \\
\hline Cation & & \\
\hline Anion & & \\
\hline
\end{tabular}

*measured at $20^{\circ} \mathrm{C}$

copolymer resin (5-6\%), 1-propanol (42-54\%), water (40-50\%), ethyl alcohol $(<8 \%)$, mixed ethers and other VOCs $(<2 \%)$ ) was purchased from Dupont (USA).

\subsection{Ionic liquids}

The ILs used in this study, 1-ethyl-3-methylimidazolium tetracyanoborate was purchased from Merck (Germany).

\subsection{Composite membranes}

The composite membranes containing the same concentrations of the IL $(50 \mathrm{wt} \%)$ and the polymer (50 wt $\%$ ) were prepared by the solution casting method described elsewhere. ${ }^{1,4)}$ The $10 \mathrm{wt} \%$ of $\mathrm{N}, \mathrm{N}$-dimethylacetamide (DMAc) was added into the polymer solutions, and then the solutions were stirred overnight. All the samples were cast in Petri dishes and were finally dried in a vacuum oven at $40^{\circ} \mathrm{C}$ for $12 \mathrm{~h}$ under no vacuum and then at $110^{\circ} \mathrm{C}$ for $12 \mathrm{~h}$ under vacuum to evaporate the solvent slowly and completely.

\subsection{Characterization}

Ionic conductivity of the composite membrane samples was measured by the four-point-probe conductivity cell described elsewhere. ${ }^{9)}$ The conductivity cell was placed 
in the head-space of a temperature controlled sealed vessel with no external humidification for the composite membraens containing EMITCB. The size of the membrane samples was $2 \mathrm{~cm}$ long and $1 \mathrm{~cm}$ wide. The impedance data for ionic conductivity of the membranes were obtained by impedance spectroscopy using a BioLogic SP-150 (France). The measurements were carried out in potentiostatic mode in the frequency range of $0.1 \mathrm{~Hz}$ to $0.5 \mathrm{MHz}$ with $5 \mathrm{mV}$ oscillating voltage. Ionic conductivity of the samples was calculated from the impedance data using the equation (1):

$$
\sigma=\frac{L}{R W d}
$$

where $\sigma$ is the ionic conductivity $\left(\mathrm{S} \mathrm{cm}^{-1}\right), L$ the distance between two potential sensing platinum wires, $R$ the membrane resistance derived from the impedance value at zero phase angle, $W$ the width between the potential sensing platinum wires and $d$ the membrane thickness. The electrochemical data were averaged using three measurements, and the standard deviation of all data was below $1 \%$.

Morphology characterization of the membranes was studied by the SAXS. SAXS experiments were performed at a Rigaku D/max-2500 $(5 \mathrm{~kW})$ with an image plate system equipped using X-rays with a wavelength of $1.5406 \AA$

The thermal stability of the thorough dried composite membranes was examined by thermogravimetric analysis (TGA) using a TGA 2050 instrument (TA instruments). Heat scans were carried out under nitrogen and a heating rate of $10^{\circ} \mathrm{C} / \mathrm{min}$ under a nitrogen atmosphere was used over the temperature range of 100 to $600^{\circ} \mathrm{C}$.

\section{Results and Discussion}

It has been reported that the composite membranes containing ionic liquids well conduct proton at anhydrous condition and elevated temperature. ${ }^{1-6)}$ Compared to the proton conduction of water swollen membranes carried out by hopping (transport by hydronium ions, $\mathrm{H}_{3} \mathrm{O}^{+}$) and vehicular (transport by diffusion of water) mechanisms, proton in the composite membranes containing ionic liquids is solely transferred by hopping between sulfonic acid groups and ionic liquids or one and another ionic liquid. However, since the movement by hopping is a few orders of magnitude faster than that by vehicular for water swollen membranes, most of protons in water swollen membranes are conducted by hopping. There is no significant difference for proton conduction mechanism between water swollen and ionic liquid impregnated membranes. Similarly, both types of membranes are necessary to form ionic cluster network to transport proton. From a point of view, it is necessary to investigates if EMITCB, which is recently attractive for applications of electrochemical devices, is able to conduct proton and form ionic cluster network. Proton conduction and formation of ionic cluster network can be confirmed by measurement of ionic conductivity and observation of ionomer peaks in SAXS.

Fig. 1 shows the ionic conductivity of the composite membranes containing EMITCB as a function of temperature. In general, the relationship between a reciprocal temperature and logarithmic ionic conductivity shows Arrhenius' activation behavior, which means linearly proportional. However, as seen in Fig. 1 there are three different behaviors with temperature range for the composite membrane. Below $353.15 \mathrm{~K}$ (2.83 in x-axis of Fig. 1), ionic conductivity slowly rises with a reciprocal temperature; in the range from 333.15 to $413.15 \mathrm{~K}$ (from 3.00 to 2.42 in x-axis of Fig. 1), a linear proportionality is observed; above $413.15 \mathrm{~K}$, ionic conductivity decreases. There is an exception for the composite membrane containing EMITCB of $50 \mathrm{wt} \%$ showing saturation of ionic conductivity followed by

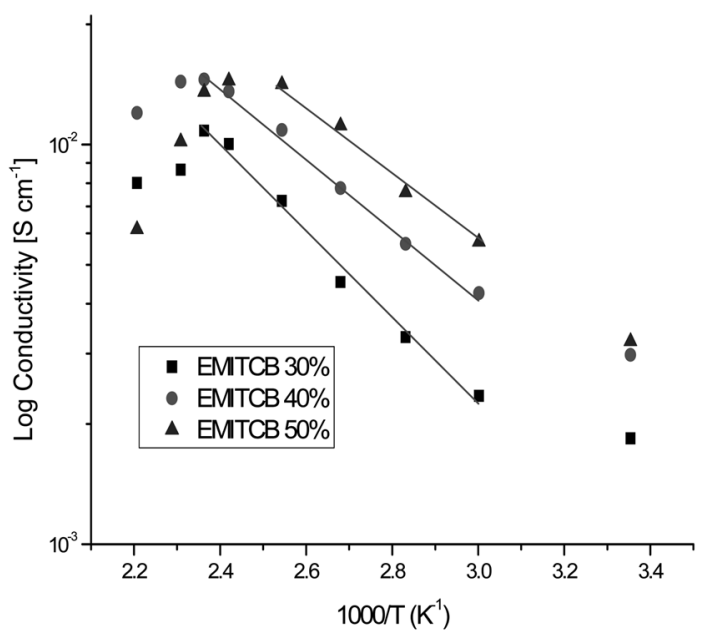

Fig. 1. Ionic conductivity of the Nafion/EMITCB composite membranes with different contents of EMITCB as a function of a reciprocal temperature. 
the decrease from $393.15 \mathrm{~K}$ (2.54 in x-axis of Fig. 1). The Arrhenius' activation behavior indicates the well formation of ionic cluster network. Thus, it is inferred that EMITCB might be not attributed to fully build up ionic cluster network in Nafion polymer less than $353.15 \mathrm{~K}$ because reorganization between the polymer and the IL is not fully carried out. In the middle temperature range, the activated Arrhenius behavior is observed, indicating good formation of ionic cluster network. Table 2 illustrates that the slope of the straight lines in Fig. 1, which is the activation energy to conduct proton, decreases as the content of EMITCB increases for the composite membranes. It indicates that more IL in the composite membranes provides more paths for ionic conduction in good agreement with literature $^{1-6)}$ Afterward, it is thought that a decrease in ionic conductivity could be decomposition of chemicals arising from EMITCB and proton in the composite membranes. Main reason of the decrease is often due to the decomposition of an acid formed by anions of ILs and proton. Fig. 2 and 3 shows the thermogravimetric analysis (TGA) curves of EMITCB and the composite membranes. As shown in Fig. 2, EMITCB shows better thermal stability than $\mathrm{EMIBF}_{4}$. No significant decomposition of EMITCB is observed up to $400^{\circ} \mathrm{C}$. Moreover, as seen in Fig. 3, there is no critical decomposition (less than $5 \%$ weight loss) of all the composite membranes with EMITCB of 30, 40 and $50 \mathrm{wt} \%$ up to $250^{\circ} \mathrm{C}$. A slight decrease is mainly attributed to the decomposition of sulfonic acid groups of Nafion polymer. It indicated that there is no decomposition of EMITCB itself and EMITCB in the composite membranes. Thus, one of influential reasons on the decrease in ionic conductivity is the decomposition of the acid formed in the composite membranes, i.e., tetracyanoboric acid. Unfortunately, it is hard to find out the information on boiling point

Table 2. Results of the slopes and activation energy calculated from the plots showing $\log \sigma$ as a function of a reciprocal temperature in Kelvin

\begin{tabular}{ccc}
\hline Composite membrane & Slope & $\begin{array}{c}\text { Activation energy } \\
\left(\mathrm{kJ} \mathrm{mol}^{-1}\right)\end{array}$ \\
\hline Nafion/EMITCB 30 wt\% & -1.088 & 9.05 \\
Nafion/EMITCB 40 wt\% & -0.871 & 7.24 \\
Nafion/EMITCB 50 wt\% & -0.750 & 6.24
\end{tabular}

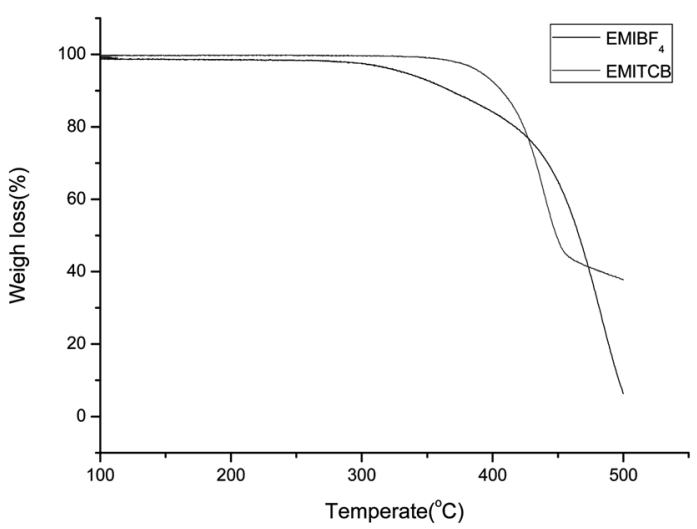

Fig. 2. Thermogravimetric analysis curves of the composite membranes containing $\mathrm{EMIBF}_{4}$ and EMITCB of $50 \mathrm{wt} \%$ under nitrogen atmosphere.

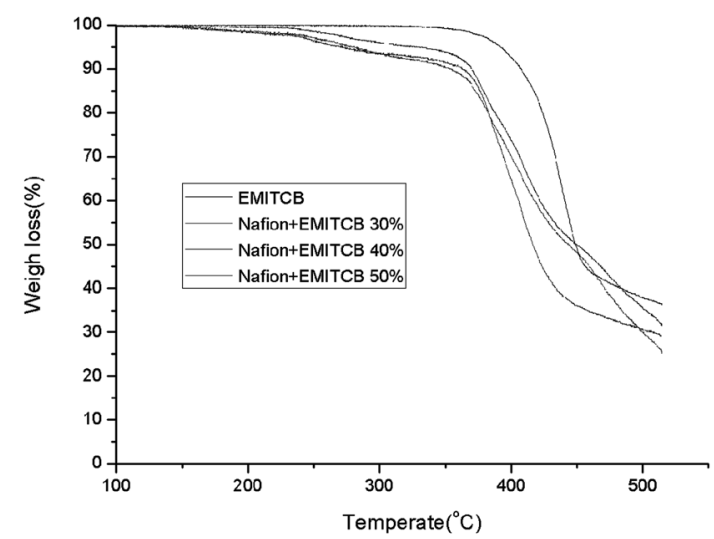

Fig. 3. Thermogravimetric analysis curves of EMITCB and the composite membranes containing different contents of EMITCB under nitrogen atmosphere.

of the acid. It could be just inferred that the acid in the composite membranes might be decomposed above $\sim 433 \mathrm{~K}$ (2.31 in x-axis of Fig. 1). It is also observed that the decomposition of the acid occurs at lower temperature at higher content of EMITCB. It is because higher content of EMITCB means higher possibility to form more concentration of the acid in the composite membranes. However, taking into account that HTPEMFCs is operated at $150^{\circ} \mathrm{C}(423.15 \mathrm{~K})$, the composite membranes with $40 \mathrm{wt} \%$ EMITCB can be used for HTPEMFCs since the ionic conductivity of the composite membranes reaches the maximum $\left(0.0146 \mathrm{~S} \mathrm{~cm}^{-1}\right)$ at $423.15 \mathrm{~K}$.

As mentioned before, proton conduction of the composite membranes confirmed by the measurement of 
ionic conductivity is mainly attributed to the formation of ionic cluster network. Ionic cluster network is a proposed structure comprised of spherical ionic clusters and connection between ionic clusters. ${ }^{10-14)}$ The formation of spherical ionic clusters in membranes is done by the reorganization of hydrophilic side chains solvated by solvents such as water (in general) or ionic liquids (in this study). SASX is usually being used to study scattering of intermolecular like scattering between clusters. Fig. 4 shows the SAXS curves of the composite membrane containing EMITCB. The SAXS profile for composite membranes containing ILs generally shows the presence of (i) an upturn in the intensity at very small $\mathrm{q}$ values $\left(<10^{-2} \AA^{-1}\right)$, (ii) matrix peak, (iii) an ionomer peak and (iv) Porod (tail) region at high $q$ values. $^{2-6)}$ Representative SAXS curves are given in Fig. 4 for the composite membrane containing EMITCB. The upturn at small $q$ values $\left(<10^{-2} \AA^{-1}\right)$ for both the membranes is not observed in the present case since scattering curve is recorded for $q$ values greater than $10^{-2} \AA^{-1}$ only. The ionomer peaks in the mid $q$ region $\left(\sim 0.09 \AA^{-1}\right)$ which is generally attributed to the presence of ionic clusters has been observed in all the composite membranes. It is, however, noted that the SAXS curve of the composite membrane containing EMITCB has a little different look compared to that of the composite membrane containing $\mathrm{EMIBF}_{4}$ shown in the recent publication. ${ }^{6}$ ) This change might bring about the different reorganization of EMITCB in the composite membrane. The ionomer peak of the annealed composite membrane becomes much smoother

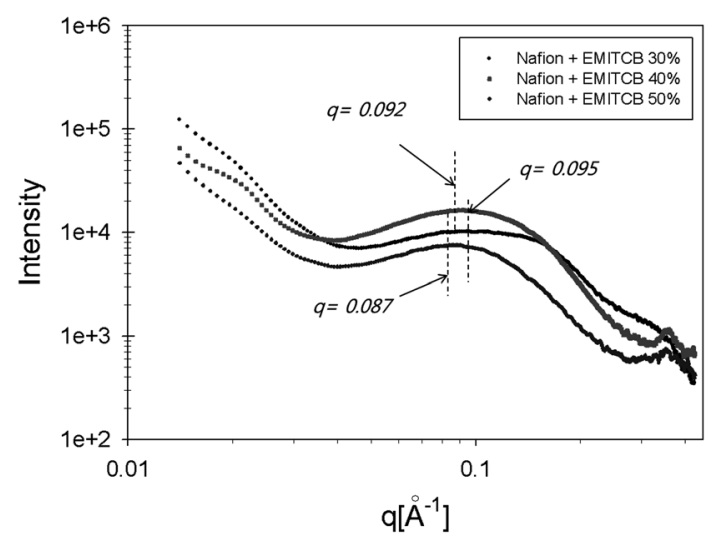

Fig. 4. SAXS spectra of the composite membranes with different contents of EMITCB. and shifts to a lower q value (cf. $\sim 0.13 \AA^{-1}$ for the composite membranes containing $\mathrm{EMIBF}_{4}{ }^{6}{ }^{6}$ ) It means that the size of an ionic cluster in the composite membranes containing EMITCB than those containing $\mathrm{EMIBF}_{4}$ is bigger (Table 3), but the cluster failed to make its edge clear. Except this, the general behavior, which shows a shift of $q_{\max }$ to lower values from 0.095 to $0.087 \AA^{-1}$ as the content of IL in composite membranes increases, in other words, an increase in cluster diameter of ionic clusters from 62.23 to $76.91 \AA$, is observed in accordance with the previous literature. ${ }^{2-6)}$ In general, bigger cluster diameter of an ionic cluster results in higher ionic conductivity, but in case of the composite membranes containing EMITCB it is valid in the middle temperature range.

\section{Conclusions}

EMITCB was used as ionic conducting medium in composite membranes containing ionic liquids for high temperature proton exchange membrane fuel cells due to its low viscosity, in other words, higher ionic conductivity than $\mathrm{EMIBF}_{4}$ which was often used for ILs of the composite membranes. It was confirmed in the observation of Arrhenius' activation behavior that the activation energy $\left(6.24 \mathrm{~kJ} \mathrm{~mol}^{-1}\right)$ of the composite membranes with EMITCB of $50 \mathrm{wt} \%$ in this study is lower than that $\left(8.1 \mathrm{~kJ} \mathrm{~mol}^{-1}\right)$ with $\mathrm{EMIBF}_{4}$ of $50 \mathrm{wt} \%$ in the previous literature. ${ }^{2)}$ However, the composite membranes containing EMITCB shows lower ionic conductivity $\left(0.0146 \mathrm{~S} \mathrm{~cm}^{-1}\right)$ than that containing $\mathrm{EMIBF}_{4}\left(0.0229 \mathrm{~S} \mathrm{~cm}^{-1}\right)$. According to the recent publication, ${ }^{1-6)}$ ionic conductivity of composite membranes containing ILs is determined by that of ILs if the same type of polymer is used, however, in this study, this rule was broken up. Further studies on

Table 3. Results of the $q$ values at the maximum intensity of ionomer peaks $\left(q_{\max }\right)$ and ionomer cluster diameter at the determined $q$ values from the SAXS of the composite membranes

\begin{tabular}{ccc}
\hline Composite membrane & $q_{\max }\left(\AA^{-1}\right)$ & Cluster diameter $(\AA)$ \\
\hline Nafion/EMITCB 30 wt\% & 0.095 & 62.23 \\
Nafion/EMITCB 40 wt\% & 0.092 & 69.05 \\
Nafion/EMITCB 50 wt\% & 0.087 & 76.91 \\
\hline
\end{tabular}


this observation are needed. So far, the possible reason to explain why the general rule is broken up might be the decomposition of tetracyanoboric acid formed by the anion of EMITCB and proton in the composite membranes. This decomposition is also needed to be studied further. Despite the possible decomposition, it can be concluded that EMITCB is able to play an important role in transferring proton through ionic cluster network in the composite membranes and the composite membrane containing EMITCB of $40 \mathrm{wt} \%$ is preferred for proton exchange membrane fuel cells at elevated temperatures with no external humidification.

\section{Acknowledgement}

This work was supported by the 2010 research fund of Sangmyung University.

\section{References}

1. E. Cho, J.-S. Park, S. S. Sekhon, G.-G. Park, T.-H. Yang, W.-Y. Lee, C.-S. Kim, and S.-B. Park, 'A Study on Proton Conductivity of Composite Membranes with Various Ionic Liquids for High-Temperature Anhydrous Fuel Cells' J. Electrochem. Soc., 156, B197 (2009).

2. S. S. Sekhon, J.-S. Park, J.-S. Baek, S.-D. Yim, T.-H. Yang, and C.-S. Kim, 'Small-angle X-ray scattering study of water free fuel cell membranes containing ionic liquids' Chem. Mater., 22, 803 (2010).

3. S. S. Sekhon, J.-S. Park, E. Cho. Y.-G. Yoon, C.-S. Kim, and W.-Y. Lee, 'Morphology studies of high temperature proton conducting membranes containing hydrophilic/ hydrophobic ionic liquids' Macromolecules, 42, 2054 (2009).

4. S. S. Sekhon, J.-S. Park, and Y.-W Choi, 'A SAXS study on nanostructure evolution in water free membranes containing ionic liquid: from dry membrane to saturation'
Phys. Chem. Chem. Phys., 12, 13763 (2010).

5. J.-S. Baek, J.-S Park, S. S. Sekhon, T.-H. Yang, Y.-G. Shul, and J.-H. Choi, 'Preparation and characterization of non-aqueous proton-conducting membranes with the low content of ionic liquids' Fuel Cells, 10, 762 (2010).

6. J.-S. Park, M.-S. Shin, S. S. Sekhon, Y.-W. Choi, and T.-H. Yang, 'Effect of annealing of Nafion recast membranes containing ionic liquids' J. Kor. Electrochem. Soc., 14, 9 (2011).

7. Q. Li, R. He, J. O. Jensen, and N. J. 'Bjerrum, Approaches and Recent Development of Polymer Electrolyte Membranes for Fuel Cells Operating above $100^{\circ} \mathrm{C} ' \mathrm{~J}$. Chem. Mater., 15, 4896-4915 (2003).

8. J. Roziere, and D. J. Jones, 'Non-fluorinated polymer materials for proton exchange membrane fuel cells' Annu. Rev. Mater. Res., 33, 503 (2003).

9. Y. Woo, S. Y. Oh, Y. S. Kang, and B. Jung, 'Synthesis and characterization of sulfonated polyimide membranes for direct methanol fuel cell' J. Membr. Sci., 220, 31 (2003).

10. T. D. Gierke, G. E. Munn, and F. C. Wilson, 'The morphology in nafion perfluorinated membrane products, as determined by wide- and small-angle x-ray studies' $J$. Polym. Sci.: Polym. Phys. Ed., 19, 1687 (1981).

11. B. Dreyfus, G. Gebel, G. P. Aldebert, M. Pineri, and M. Escoubes, 'Distribution of the «micelles » in hydrated perfluorinated ionomer membranes from SANS experiments' J. Phys. France, 51, 1341 (1990).

12. G. Gebel and J. Lambard, 'Small-Angle Scattering Study of Water-Swollen Perfluorinated Ionomer Membranes' Macromolecules, 30, 7914 (1997).

13. S. Kumar and M. Pineri, 'Interpretation of small-angle $\mathrm{x}$ ray and neutron scattering data for perfluorosulfonated ionomer membranes' J. Polym. Sci. B, 24, 1767 (1986).

14. A. S. Ioselevich, A. A. Kornyshev, and J. H. G. Steinke, 'Fine Morphology of Proton-Conducting Ionomers' $J$. Phys. Chem. B, 108, 11953 (2004).

15. Product catalogue "In search of tomorrow's innovations?: Ionic liquid for electrochemical applications" from Merck. 